\title{
Adequate sedation with single-dose dexmedetomidine in patients undergoing transurethral resection of the prostate with spinal anaesthesia: a dose-response study by age group
}

\author{
Jeongmin Kim, Won Oak Kim, Hye-Bin Kim and Hae Keum Kil
}

\begin{abstract}
Background: Dexmedetomidine (DMT), a highly selective a2-adrenoceptor agonist, has been used safely as a sedative in patients under regional anesthesia. The purpose of this study was to determine the $50 \%$ effective dose $\left(E D_{50}\right)$ of single-dose DMT to induce adequate light sedation in elderly patients in comparison with younger patients undergoing transurethral resection of the prostate (TURP) with spinal anesthesia.

Methods: Forty-two male patients were recruited. The young age group (Group Y) included patients 45 to 64 years old and the old age group (Group O) included patients 65 to 78 years old. After the spinal anesthesia was performed, a pre-calculated dose of DMT was administered for 10 min. The Observer's Assessment of Alertness/Sedation (OAA/S) scale, bispectral index score (BIS) were assessed then at 2-min intervals for 20 min. A modified Dixon's up-and-down method was used to determine the $\mathrm{ED}_{50}$ of the drug for light sedation (OAA/S score 3/4). In the recovery room, regression times of the motor and sensory blocks were recorded.
\end{abstract}

Results: The ED $\mathrm{E}_{50}$ of DMT was 0.25 (95\% C.I. 0.15-0.35) $\mu \mathrm{g} / \mathrm{kg}$ in Group O and 0.35 (95\% C.I. 0.35-0.45) $\mu \mathrm{g} / \mathrm{kg}$ in Group Y $(p=0.002)$. The $\mathrm{ED}_{95}$ was $33 \%$ lower in Group O compare with Group Y (0.38 (95\% C.I. 0.29-0.39) $\mu \mathrm{g} / \mathrm{kg}$ vs. 0.57 (95\% C.I. $0.49-0.59) \mathrm{\mu g} / \mathrm{kg})$. The regression time of sensory block was longer in Group O than in Group Y $(109.0 \pm 40.2 \mathrm{~min}$ vs. $80.0 \pm 31.6 \mathrm{~min})(p=0.014)$.

Conclusion: The single-dose of DMT for light sedation was lower by $21 \%$ in Group O compare with Group Y underwent TURP with spinal anesthesia.

Trial registration: ClinicalTrials.gov identifier: NCT01665586. Registered July 31, 2012.

Keywords: Dexmedetomidine, Aged, Sedation, Spinal anesthesia

\section{Background}

Although spinal block is the most common anesthetic method for transurethral resection of the prostate (TURP), patients may still experience adverse effects during surgery. Satisfactory sedation relieves a patient's psychological and physiological stress and increases the patient's acceptance of regional anesthesia. However,

\footnotetext{
* Correspondence: hkkil@yuhs.ac

Department of Anesthesiology and Pain Medicine, Severance Hospital, Anesthesia and Pain Research Institute, Yonsei University College of
} Medicine, Seoul, Republic of Korea excessive sedation can cause adverse cardiorespiratory effects, masking the early signs of TURP syndrome, [1,2] and even increase the incidence of postoperative delirium in elderly patients $[3,4]$. Our challenge was to induce appropriately light sedation during TURP with spinal anesthesia, while maintaining the patient's arousability, cooperativity, and cardiopulmonary stability.

Dexmedetomidine (DMT), a potent and highly selective $\alpha 2$-adrenoceptor agonist, has been safely used to sedate patients under regional anesthesia [5-7]. DMT induces potent sedation through its action on the locus

\section{Biomed Central}


coeruleus, the predominant brainstem nucleus involved in sleep regulation and respiratory control [8]. Compared to traditional sedatives such as midazolam and propofol, patients treated with DMT have better arousability and cooperation, minimal respiratory depression, $[9,10]$ and better postoperative cognitive function. Moreover, intravenous DMT hastens the onset and prolongs the duration of spinal block [11-13]. Thus, DMT could be a useful alternative for sedation in patients undergoing TURP with low-dose spinal anesthesia. DMT is usually given initially as a bolus, followed by continuous infusion. Single-dose DMT can also provide adequate sedation during short procedures under spinal anesthesia [7,11-15]. However, previous literature investigating the single-dose use of DMT for sedation during spinal anesthesia in elderly patients is scarce $[7,11]$.

The aim of this study was to determine the $50 \%$ effective dose $\left(E D_{50}\right)$ and $95 \%$ effective dose $\left(E D_{95}\right)$ of single-dose DMT to induce adequate sedation in elderly patients compared to those in younger patients undergoing TURP with spinal anesthesia.

\section{Methods}

\section{Clinical setting}

The present study was performed at Severance Hospital from July 2012 to December 2013. This study was conducted in accordance with principles of Good Clinical Practice and was approved by the Institutional Research Board of Severance Hospital (reference number 4-20110927) and all patients gave written informed consent. The study was registered at ClinicalTrails.Gov with the number NCT01665586. The patients were fully informed the sedation assessment during spinal anesthesia. Exclusion criteria included the infection on puncture sites, coagulopathy disorders, allergy to local anesthetics, psychiatric history, and neurological diseases. Forty-two patients of ASA physical status I or II and who were scheduled to undergo elective TURP were recruited. Subjects were divided into two groups by the patient's age. Patients in the young age group (Group Y) were between 45 and 64 years old and those in the old age group (Group O) were 65 to 78 years old. One anesthesiologist prepared the study drug (DMT) in a preparation room. All patients and the observational investigators were blinded to the administered dose of DMT. One millilitre $(100 \mu \mathrm{g})$ of DMT (Precedex ${ }^{\oplus}$, Hospira Inc., Lake Forest, USA) was diluted with $49 \mathrm{ml}$ of normal saline $(2 \mu \mathrm{g} / \mathrm{ml})$ in a $50 \mathrm{ml}$ syringe.

\section{Spinal anesthesia}

No premedication was given. Standard monitors and bispectral index (BIS) monitors (BIS vista monitor Revision 3.0, Aspect Medical Systems, Norwood, MA, USA) were applied in the operating room. Prior to spinal block,
$300 \mathrm{ml}$ of lactated Ringer's solution was administrated intravenously. Spinal puncture was performed with a 25 gauge Quincke needle at L3/4 in lateral decubitus position. After confirmation of free-flow and clear cerebrospinal fluid, $6 \mathrm{mg}$ of hyperbaric bupivacaine (Marcaine ${ }^{\oplus}$ Spinal Heavy: Astra, Sodertalje, Sweden) was administered intrathecally over $10-15 \mathrm{~s}$. The pin-prick test was performed then every $2 \mathrm{~min}$ at the mid-thoracic line bilaterally. The peak block level was defined as the same block level that persisted at four consecutive pin-prick tests. When the peak sensory block was determined, the degree of motor block was assessed using a modified Bromage Scale (in which $0=$ no paralysis; $1=$ unable to raise extended leg; $2=$ unable to flex knee; $3=$ unable to flex ankle) [16]. After the lithotomy position was done for surgical preparation, the pre-calculated amount of DMT solution was infused for 10 min using an infusion pump (Orchestra ${ }^{\circ}$ Module DPS, Fresenius Vial S. A. S. Le Grand Chemin 38590 Brézins, France). A modified Dixon's up-and-down method was used to determine the $\mathrm{ED}_{50}$ of DMT to obtain a light sedation level of an Observer's Assessment of Alertness/Sedation scale (OAA/S) 4/3 [17]. After the infusion was completed, a second anesthesiologist evaluated the OAA/S scales, BIS scores, and vital signs every 2-min intervals for $20 \mathrm{~min}$. The initial DMT dose in the first patient was $0.6 \mu \mathrm{g} / \mathrm{kg}$. If the patient had a lethargic response when his name was called in a normal tone or responds only after name is spoken loudly or repeatedly (OAA/S scale 4/3) at any time point of assessment, it was defined as a successful sedation (Table 1) [18]. If the patient showed the OAA/S scale $\leq 2$, he was awakened with tactile stimulation. If targeted sedation $(\mathrm{OAA} / \mathrm{S}<5)$ was not obtained within 20 minutes, it was defined as failed sedation. Depending on the responses, the subsequent dose of DMT was decreased or increased by $0.1 \mu \mathrm{g} / \mathrm{kg}$ for the next patient in a stepwise fashion. Recruitment continued until six independent pairs (from successful sedation to failed sedation) would give a reliable estimation of the adequate light sedation dose of DMT in each group. Mean arterial pressure (MAP), heart rate (HR), and $\mathrm{SpO}_{2}$ were recorded every 5 minutes during anesthesia, at the end of surgery, at arrival and $30 \mathrm{~min}$ of the post anesthetic care unit (PACU).

Table 1 Observer's assessment of alertness/sedation scale [17]

\begin{tabular}{lr}
\hline 1 & Does not respond to mild prodding or shaking \\
2 & Responds to mild prodding or shaking \\
3 & Responds only after name is spoken loudly or repeatedly \\
4 & Lethargic response to name spoken in normal tone \\
5 & Responds readily to name spoken in normal tone \\
\hline
\end{tabular}


Hypotension was defined as $\mathrm{MAP}<60 \mathrm{mmHg}$ or a $>$ $30 \%$ decrease from the baseline value. Bradycardia was defined as heart rate $<45 \mathrm{bpm}$. Hypotension or bradycardia was treated with intravenous ephedrine or atropine. When the $\mathrm{SpO}_{2}$ was $<92 \%$, supplemental oxygen was given via face mask.

In the PACU, the times to sensory regression of 2dermatomes and to motor recovery to a Bromage scale of 0 were evaluated. Postoperative pain was assessed using a verbal numerical rating scale (vNRS: $0=$ no pain; $10=$ worst possible pain) at 6 and $24 \mathrm{~h}$ postoperatively. Pain $\geq 5$ vNRS was treated with $50 \mathrm{mg}$ of intravenous tramadol. The time to the first analgesic request was recorded.

\section{Statistical analysis}

Statistical analysis was performed using PASW Statistics $19^{\mathrm{mm}}$ (SPSS Inc., Chicago, IL, U.S.A.). Data was analysed by isotonic regression using the pooled-adjacent-violators algorithm (PAVA) to interpolate $\mathrm{ED}_{50}$ (83\% C.I.) and $\mathrm{ED}_{95}$ (95\% C.I.). Independent t-tests, chi-square tests, Fisher's exact tests, or Mann-Whitney tests were used to compare complication rates, and postoperative pain scores between the two groups. A linear mixed model was used to analyse the hemodynamic variables across the two groups. In each group, MAP and HR changes were compared to baseline values using t-tests. The correlation of the BIS and the OAA/S scale was analyzed with a mixed model in each group. Values are expressed as mean \pm standard deviation (SD), mean (95\% C.I.), or as numbers. Each investigation of two groups was carried out by Dixon's up-and-down method. The sample size was based on Dixon's method, which requires at least six pairs of failure-success to calculate half maximal effective concentration $\left(\mathrm{EC}_{50}\right)$ [19]. Patients were recruited until six pairs of consecutive up and down (success and failure) adjustment of the DMT dose was achieved. Statistical significance was defined by a $P$ value $<0.05$

\section{Results}

The sequences of successful and failed sedation are presented in Figure 1. The estimated $\mathrm{ED}_{50}$ of DMT was significantly different between the old and young groups [0.25 (95\% C.I. 0.15-0.35) $\mu \mathrm{g} / \mathrm{kg}$ vs. 0.35 (95\% C.I. 0.35$0.45) \mu \mathrm{g} / \mathrm{kg}, p<0.05]$. When the values were interpolated using isotonic regression with PAVA and the bootstrap method, the $\mathrm{ED}_{50}\left(83 \%\right.$ C.I.) and $\mathrm{ED}_{95}$ (95\% C.I.) of DMT were still significantly different between Group $\mathrm{O}$ and Group Y (Table 2).

In both groups, MAP gradually decreased after the DMT infusion, but heart rate decreased continuously during the experiment compared to the baseline values $(p<0.05)$ (Figure 2). By linear mixed model analysis, the MAP of Group O decreased significantly more than that of Group Y $(p<0.05)$, but heart rate was not significantly different between the two groups $(p>0.05)$.

Forty-two patients were enrolled (Group $\mathrm{Y}=22$, Group $\mathrm{O}=20$ ) (Figure 3). Mean age of Group Y was 58 years old, whereas that of Group $\mathrm{O}$ was 72 years old. Patients' height, weight and BSA were similar between the groups (each $p>0.05$ ). The duration of surgery, maximum sensory block level and baseline hemodynamics were not significantly different between the groups (each $p>0.05$ ). Comorbidities (including hypertension, diabetes mellitus, coronary artery disease and other diseases) were present in $85 \%$ of patients in Group $\mathrm{O}$ and $41 \%$ of patients in Group Y. The sensory block regression time was longer in Group $\mathrm{O}$ than in Group $\mathrm{Y}$ $(109.0 \pm 40.2 \mathrm{~min} v s$. $80.0 \pm 31.6 \mathrm{~min}, p<0.05)$, but motor recovery time was similar in both groups. Postoperative 6 hours pain score was low in Group O compare with the Group Y $(2.1 \pm 0.8$ vs. $3.2 \pm 2.0, p<0.05)$. But no difference showed in postoperative 24 hrs (Group O vs. Group Y, $1.4 \pm 0.8$ vs. $1.9 \pm 1.5, p>0.05)$. Transient hypotension occurred after DMT infusion in $27.3 \%$ of Group O (6/22) and 35\% in Group Y (7/20). These hypotensive events were self-limited and ephedrine was

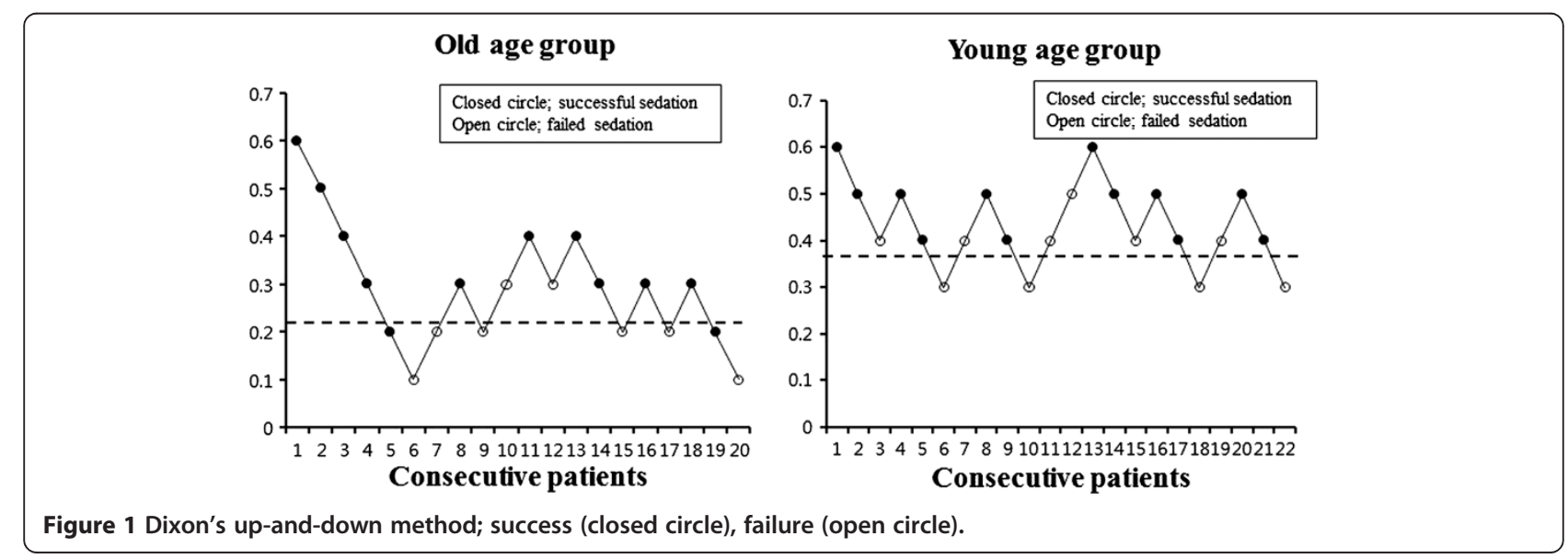


Table 2 Dixon's method and isotonic regression

\begin{tabular}{llc}
\hline Drug dose $(\boldsymbol{\mu g} / \mathbf{k g})$ & Group Y $(\boldsymbol{n}=\mathbf{2 2})$ & Group O $(\boldsymbol{n}=\mathbf{2 0})$ \\
\hline Dixon's method & & \\
$\mathrm{ED}_{50}(95 \%$ C.I.) & $0.35(0.35-0.45)$ & $0.25(0.15-0.35)$ \\
Isotonic regression method & & \\
$\mathrm{ED}_{50}(83 \%$ C.I.)† & $0.41(0.38-0.45)$ & $0.24(0.19-0.3)$ \\
$\mathrm{ED}_{95}(95 \%$ C.I.)‡ & $0.57(0.49-0.59)$ & $0.38(0.29-0.39)$ \\
\hline
\end{tabular}

$\mathrm{ED}_{50} ; 50 \%$ effective dose, $\mathrm{ED}_{95} ; 95 \%$ effective dose, C.l.; confidence interval Dixon's method $p$ value (non-parametric): 0.009 .

†lsotonic regression method $83 \%$ Confidence interval: do not overlap.

flsotonic regression method $95 \%$ Confidence interval: do not overlap. not administered. In two patients of Group $\mathrm{Y}$, the $\mathrm{SpO}_{2}$ decreased below 92\% during DMT infusion but was improved with $\mathrm{O}_{2}$ administration. No one showed OAA/S $\leq 2$ during the procedure. BIS and OAA/S were moderately associated in the Group $\mathrm{O}$ and strongly associated in the Group Y during sedation. $(\mathrm{r}=0.489, p<0.05$ vs. $\mathrm{r}=0.604$, $p<0.05)$.

\section{Discussions}

The first question in this study sought to determine the $50 \%$ effective dose $\left(E_{50}\right)$ and $95 \%$ effective dose $\left(E_{95}\right)$ of single-dose DMT to induce adequate sedation in elderly patients undergoing TURP with spinal anesthesia. The current study found that the $\mathrm{ED}_{95}$ of a single-dose DMT to induce light sedation was $0.38 \mu \mathrm{g} / \mathrm{kg}$ (95\% C.I.
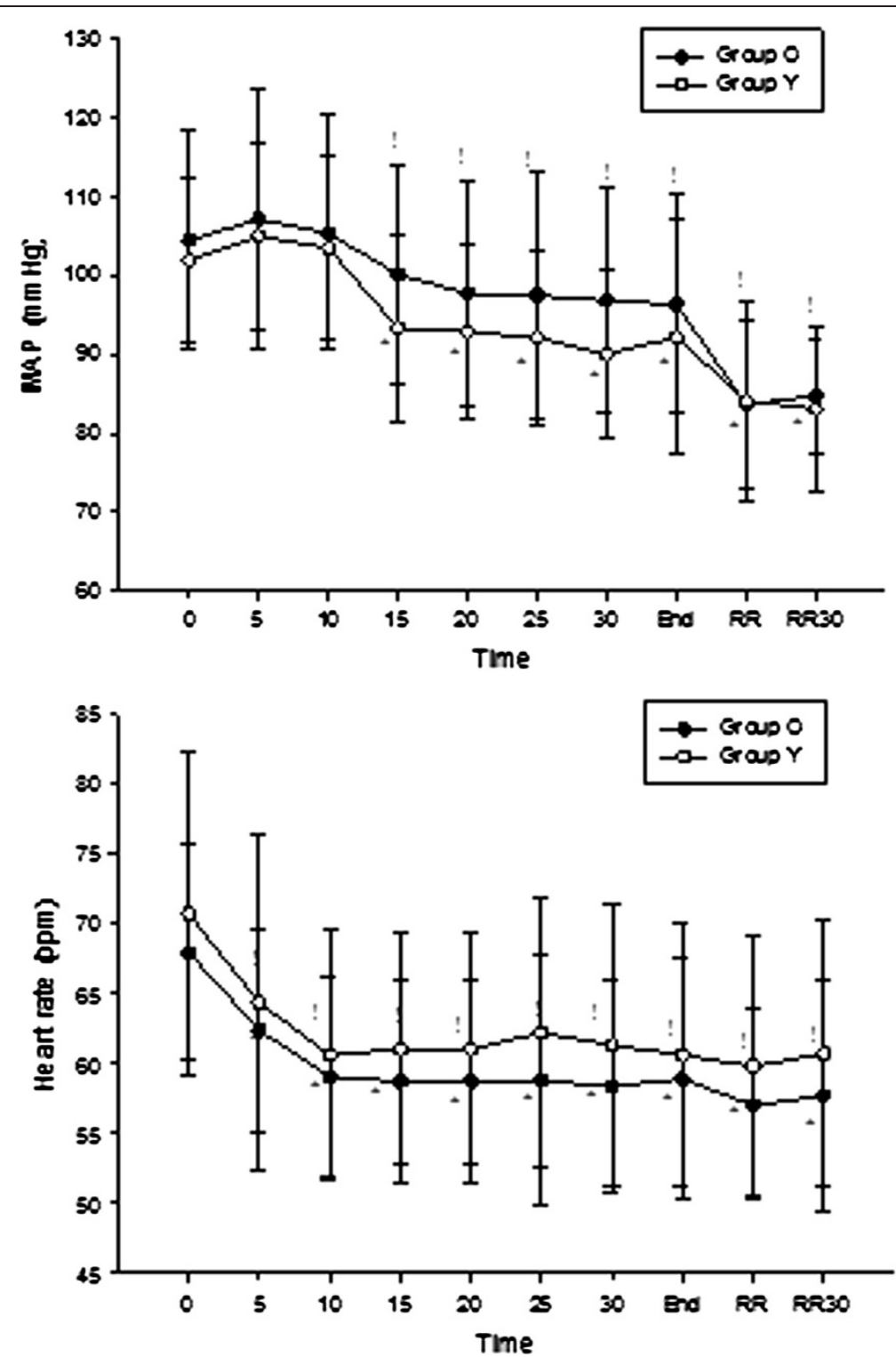

Figure 2 Intraoperative hemodynamic changes. 


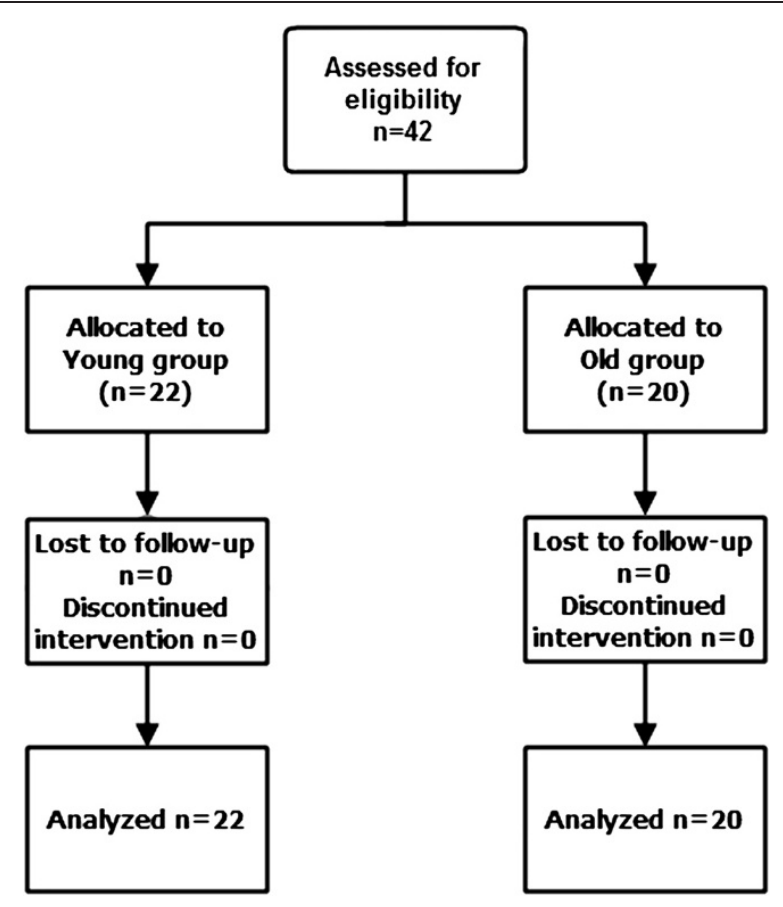

Figure 3 Consort diagram.

0.29-0.39) in elderly patients over 65 years old and $0.57 \mu \mathrm{g} / \mathrm{kg}$ (95\% C.I. 0.49-0.59) in patients between 45 and 64 years old. The most important clinically relevant finding was the $\mathrm{ED}_{95}$ of single-dose DMT in elderly patients was $67 \%$ that of younger patients.

Manufacturer suggests that sedation with DMT can be achieved with $0.2-0.7 \mu \mathrm{g} / \mathrm{kg} / \mathrm{hr}$ after $1.0 \mu \mathrm{g} / \mathrm{kg}$ loading dosage [20]. However, in elderly patients, excessive sedation can easily occur when recommend dosage of DMT was used. Park et al. found that excessive sedation with a Ramsay score of $5 / 6$ occurred in $46 \%$ of patients treated with $0.5 \mu \mathrm{g} / \mathrm{kg}$ DMT and $60 \%$ of patients treated with $1 \mu \mathrm{g} / \mathrm{kg}$ DMT in elderly patients [11]. In comparison, none of the 30- to 40-year-old patients showed excessive sedation of OAA/S $\leq 2$ after a $0.5 \mu \mathrm{g} / \mathrm{kg}$ DMT infusion [15]. Therefore, minimal optimum dose of DMT to avoid over sedation should be determined in elderly patients. The findings of this study suggest that we should reduce the dose of DMT for elderly patients as one third of recommend dose for young patients. These results match those observed in earlier studies that suggest that the required dosage of DMT in elderly patients is half that of the recommended young adult dose [21,22].

Although, these findings cannot be extrapolated to all patients, the present study provides additional evidence with respect to pharmacokinetics of DMT in elderly patient undergoing spinal anesthesia. Generally, elderly patients are more sensitive to sedative agents. Less medication is usually required to achieve a desired clinical effect, and drug effect is often more pronounced and prolonged than we expected. However, to date there has been little agreement on the dosage of DMT in elderly patient undergoing neuraxial blockade or peripheral blockade. Whilst this study did not confirm the pharmacokinetics of DMT, it would be helpful to set out a practical guideline of DMT for the elderly patient undergoing neuraxial blockade or peripheral blockade. If a planned regional blockade is done successfully, a relatively small single-bolus dose of DMT $<0.5 \mu \mathrm{g} / \mathrm{kg}$ would be needed to reduce discomfort, anxiety and restless in elderly patients undergoing surgical procedure within 30 minutes.

There are several possible explanations for this result. First of all, spinal anesthesia may increase sensitivity to a sedative agent, explaining the low $\mathrm{ED}_{95}$ for an OAA/S sedation scale [23]. Since Tverskoy et al. reported that spinal block with bupivacaine decreased the hypnotic requirement of midazolam, thiopental, and propofol, $[24,25]$ several studies have confirmed these findings $[23,26,27]$. Especially in the early stage of spinal block, spinal anesthesia decreases afferent input and this reduces the sedative hypnotic requirement. Another possible explanation for this is that spinal analgesic spread is greater and analgesic recovery is prolonged in elderly patients as compared to younger patients [28-31]. These characteristics may be related to the different pharmacokinetic and pharmacodynamic properties of local anesthetics with advancing age.

Most studies in the field of DMT have only focussed on the sedative dose as a general intravenous anesthetic, few studies have investigated single-dose DMT use in 
spinal anesthesia. Three randomized controlled studies reported that single-dose DMT $(0.25 \mu \mathrm{g} / \mathrm{kg}, 0.5 \mu \mathrm{g} / \mathrm{kg}$, or $1 \mu \mathrm{g} / \mathrm{kg}$ ) improved spinal anesthesia by increasing block duration, increasing postoperative analgesia and achieving patient satisfaction $[7,11,15]$. Intravenous DMT is known to prolong the anesthetic duration and improve the analgesic characteristics associated with spinal block [7,11-14]. Although the underlying mechanism for this is still unclear, supraspinal, direct analgesic, and vasoconstricting effects are thought to be involved $[9,12]$. We found that sensory block duration was longer in the old age group than the young age group (109.0 \pm $40.2 \mathrm{~min}$ vs. $80.0 \pm 31.6 \mathrm{~min}$ ) despite similar peak sensory block levels. These results are consistent with those of other studies.

One unanticipated finding was that BIS and OAA/S were moderately associated in the Group $\mathrm{O}$ and strongly associated in the Group Y during sedation. Although, there were significant correlations between $\mathrm{OAA} / \mathrm{S}$ and BIS (Group O, $\mathrm{r}=0.489, p<0.05$ vs. Group $\mathrm{Y}, \mathrm{r}=0.604$, $p<0.05$ ), we thought this statistical correlation between BIS values and OAA/S scores may not be meaningful in this dose-response study. Several studies have demonstrated that BIS is not a sensitive tool for measuring sedation induced with spinal anesthesia [18]. Furthermore, it has age-dependent differences, [32,33]. Accordingly, we used BIS as an adjunctive for clinical reference to the $\mathrm{OAA} / \mathrm{S}$ scale. EEG-based monitors did not reliably distinguish between light and deep sedation [34]. Because, our targeted sedation depth was OAA/S 3/4, relatively light sedation, BIS value could not be appropriate in this setting. In addition, Kasuya et al. reported a discrepancy between OAA/S and BIS scoring when DMT was used as the sedative agent [35] and elderly patients may lose consciousness at a higher BIS score than do young adults [33]. Therefore, these results need to be interpreted with caution.

\section{Conclusions}

In conclusion, our results suggest that a single-dose of DMT for elderly patients undergoing spinal anesthesia for TURP should be reduced to two-thirds of the dose for younger patient. However, careful hemodynamic monitoring is imperative in elderly patients administered DMT for sedation under regional anesthesia, because small doses of DMT $(<0.3 \mu \mathrm{g} / \mathrm{kg})$ can result in bradycardia and hypotension.

\footnotetext{
Abbreviations

BIS: Bispectral index score; DMT: Dexmedetomidine; HR: Heart rate; MAP: Mean arterial pressure; OAA/S: Observer's Assessment of Alertness/ Sedation scale; PACU: Post anesthetic care unit; PAVA: Pooled-adjacentviolators algorithm; TURP: Transurethral resection of the prostate; VNRS: verbal numerical rating scale.
}

\section{Competing interests}

The authors declare that they have no competing interests.

\section{Authors' contributions}

JMK: Study design and patient recruitment and writing up of the first draft of the paper; WOK: reviewing the analysis of the data, approving the final manuscript; HBK: Patient recruitment and collecting the data; HKK: Study design, conducting the study and writing the manuscript. All authors read and approved the final manuscript.

\section{Acknowledgement}

We would like to thank statistical assistant, Ms Lee Hye Sun, for her help with the data analysis.

Received: 18 September 2014 Accepted: 15 January 2015

Published: 27 January 2015

\section{References}

1. Alaali HH, Irwin MG. Anaesthesia for urological surgery. Anaesth Intensive Care Med. 2012;13(7):343-7.

2. Hahn RG. Fluid absorption in endoscopic surgery. Br J Anaesth. 2006;96(1):8-20.

3. Brown CH, Azman AS, Gottschalk A, Mears SC, Sieber FE. Sedation depth during spinal anesthesia and survival in elderly patients undergoing hip fracture repair. Anesth Analg. 2014;118(5):977-80.

4. Sieber FE, Zakriya KJ, Gottschalk A, Blute MR, Lee HB, Rosenberg PB, et al. Sedation depth during spinal anesthesia and the development of postoperative delirium in elderly patients undergoing hip fracture repair. Mayo Clin Proc. 2010;85(1):18-26.

5. Song J, Kim WM, Lee SH, Yoon MH. Dexmedetomidine for sedation of patients undergoing elective surgery under regional anesthesia. Korean $J$ Anesthesiol. 2013;65(3):203-8.

6. Senses E, Apan A, Kose EA, Oz G, Rezaki H. The effects of midazolam and dexmedetomidine infusion on peri-operative anxiety in regional anesthesia. Middle East J Anesthesiol. 2013;22(1):35-40.

7. Hong JY, Kim WO, Yoon Y, Choi Y, Kim SH, Kil HK. Effects of intravenous dexmedetomidine on low-dose bupivacaine spinal anaesthesia in elderly patients. Acta Anaesthesiol Scand. 2012;56(3):382-7.

8. Hsu YW, Cortinez LI, Robertson KM, Keifer JC, Sum-Ping ST, Moretti EW, et al. Dexmedetomidine pharmacodynamics: part I: crossover comparison of the respiratory effects of dexmedetomidine and remifentanil in healthy volunteers. Anesthesiol. 2004;101(5):1066-76.

9. Ebert TJ, Hall JE, Barney JA, Uhrich TD, Colinco MD. The effects of increasing plasma concentrations of dexmedetomidine in humans. Anesthesiol. 2000;93(2):382-94.

10. Cooper L, Candiotti K, Gallagher C, Grenier E, Arheart KL, Barron ME. A randomized, controlled trial on dexmedetomidine for providing adequate sedation and hemodynamic control for awake, diagnostic transesophageal echocardiography. J Cardiothorac Vasc Anesth. 2011;25(2):233-7.

11. Park SH, Shin YD, Yu HJ, Bae JH, Yim KH. Comparison of two dosing schedules of intravenous dexmedetomidine in elderly patients during spinal anesthesia. Korean J Anesthesiol. 2014;66(5):371-6.

12. Kaya FN, Yavascaoglu B, Turker G, Yildirim A, Gurbet A, Mogol EB, et al. Intravenous dexmedetomidine, but not midazolam, prolongs bupivacaine spinal anesthesia. Can J Anaesth. 2010:57(1):39-45.

13. Abdallah FW, Abrishami A, Brull R. The facilitatory effects of intravenous dexmedetomidine on the duration of spinal anesthesia: a systematic review and meta-analysis. Anesth Analg. 2013;117(1):271-8.

14. Ok HG, Baek SH, Baik SW, Kim HK, Shin SW, Kim KH. Optimal dose of dexmedetomidine for sedation during spinal anesthesia. Korean J Anesthesiol. 2013;64(5):426-31.

15. Jung SH, Lee SK, Lim KJ, Park EY, Kang MH, Lee JM, et al. The effects of single-dose intravenous dexmedetomidine on hyperbaric bupivacaine spinal anesthesia. J Anesth. 2013;27(3):380-4.

16. Bromage PR. A comparison of the hydrochloride and carbon dioxide salts of lidocaine and prilocaine in epidural analgesia. Acta Anaesthesiol Scand Suppl. 1965;16:55-69.

17. Stylianou M, Flournoy N. Dose finding using the biased coin up-and-down design and isotonic regression. Biometrics. 2002;58(1):171-7.

18. Pollock JE, Neal JM, Liu SS, Burkhead D, Polissar N. Sedation during spinal anesthesia. Anesthesiol. 2000;93(3):728-34. 
19. Dixon WJ. Staircase bioassay: the up-and-down method. Neurosci Biobehav Rev. 1991;15(1):47-50.

20. Korea Pharmaceutical Information C. Precedex ${ }^{\oplus}$ (dexmedetomidine hydrochloride) injection: prescribing information. 2014.

21. Hoy SM, Keating GM. Dexmedetomidine: a review of its use for sedation in mechanically ventilated patients in an intensive care setting and for procedural sedation. Drugs. 2011;71(11):1481-501.

22. lirola T, Ihmsen H, Laitio R, Kentala E, Aantaa R, Kurvinen JP, et al. Population pharmacokinetics of dexmedetomidine during long-term sedation in intensive care patients. Br J Anaesth. 2012;108(3):460-8.

23. Gentili M, Huu PC, Enel D, Hollande J, Bonnet F. Sedation depends on the level of sensory block induced by spinal anaesthesia. Br J Anaesth. 1998;81(6):970-1.

24. Tverskoy M, Shagal M, Finger J, Kissin I. Subarachnoid bupivacaine blockade decreases midazolam and thiopental hypnotic requirements. J Clin Anesth. 1994;6(6):487-90.

25. Tverskoy M, Fleyshman G, Bachrak L, Ben-Shlomo I. Effect of bupivacaineinduced spinal block on the hypnotic requirement of propofol. Anaesth. 1996:51(7):652-3.

26. Morley AP, Chung DC, Wong AS, Short TG. The sedative and electroencephalographic effects of regional anaesthesia. Anaesth. 2000;55(9):864-9.

27. Marucci M, Diele C, Bruno F, Fiore T. Subarachnoid anaesthesia in caesarean delivery: effects on alertness. Minerva Anestesiol. 2003;69(11):809-19. 819-824.

28. Veering BT, Burm AG, Vletter AA, van den Hoeven RA, Spierdijk J. The effect of age on systemic absorption and systemic disposition of bupivacaine after subarachnoid administration. Anesthesiol. 1991;74(2):250-7.

29. Veering BT, Burm AG, Spierdijk J. Spinal anaesthesia with hyperbaric bupivacaine. Effects of age on neural blockade and pharmacokinetics. Br J Anaesth. 1988;60(2):187-94

30. Racle JP, Benkhadra A, Poy JY, Gleizal B. Spinal analgesia with hyperbaric bupivacaine: influence of age. $\mathrm{Br} J$ Anaesth. 1988;60(5):508-14.

31. Veering BT, Burm AG, van Kleef JW, Hennis PJ, Spierdijk J. Spinal anesthesia with glucose-free bupivacaine: effects of age on neural blockade and pharmacokinetics. Anesth Analg. 1987:66(10):965-70.

32. Yamashita K, Terao Y, Inadomi C, Takada M, Fukusaki M, Sumikawa K. Agedependent relationship between bispectral index and sedation level. J Clin Anesth. 2008;20(7):492-5.

33. Lysakowski C, Elia N, Czarnetzki C, Dumont L, Haller G, Combescure C, et al. Bispectral and spectral entropy indices at propofol-induced loss of consciousness in young and elderly patients. Br J Anaesth. 2009;103(3):387-93.

34. Chisholm CJ, Zurica J, Mironov D, Sciacca RR, Ornstein E, Heyer EJ. Comparison of electrophysiologic monitors with clinical assessment of level of sedation. Mayo Clin Proc. 2006;81(1):46-52.

35. Kasuya Y, Govinda R, Rauch S, Mascha EJ, Sessler DI, Turan A. The correlation between bispectral index and observational sedation scale in volunteers sedated with dexmedetomidine and propofol. Anesth Analg. 2009;109(6):1811-5.

doi:10.1186/1471-2253-15-17

Cite this article as: Kim et al: Adequate sedation with single-dose dexmedetomidine in patients undergoing transurethral resection of the prostate with spinal anaesthesia: a dose-response study by age group. BMC Anesthesiology 2015 15:17.

\section{Submit your next manuscript to BioMed Central and take full advantage of:}

- Convenient online submission

- Thorough peer review

- No space constraints or color figure charges

- Immediate publication on acceptance

- Inclusion in PubMed, CAS, Scopus and Google Scholar

- Research which is freely available for redistribution 